\title{
Effect of prolonged exercise on the passage of a solid meal through the stomach and small intestine
}

\author{
J CAMMACK, N W READ, ${ }^{*} \mathrm{P}$ A CANN, B GREENWOOD, and A M HOLGATE \\ From the Department of Physiology, University of Sheffield, and Gastrointestinal Unit, Royal Hallamshire \\ Hospital, Sheffield
}

SUMmARY The effect of intermittent moderate exercise on the passage of a solid meal, labelled with radioactive Technetium sulphur colloid, through the stomach and small intestine was investigated by paired studies on seven healthy volunteers. Measurements of gastric radioactivity and breath hydrogen excretion were recorded every 10 minutes while subjects exercised in a controlled manner while seated on a bicycle ergometer. These were compared with values obtained during a separate experiment while the same subjects sat upright in a chair. Exercise significantly accelerated gastric emptying (control $t \frac{1}{2}=1 \cdot 5 \pm 0 \cdot 1 \mathrm{~h}$; exercise $t \frac{1}{2}=1 \cdot 2 \pm 0 \cdot 1 \mathrm{~h} ; \mathrm{p}<0 \cdot 02$ ) but had no significant effect on small bowel transit time.

Comparatively little is known about the effects of exercise on the function of the gastrointestinal tract. Gastric secretion is inhibited during moderate or severe exercise; ${ }^{1}$ gastric emptying of liquids has been variously reported as being accelerated, ${ }^{12}$ delayed, ${ }^{12}$ or unchanged, ${ }^{3}$ depending in part on the severity of the exercise and whether it preceded or succeeded the ingestion of fluid. Despite dramatic decreases in intestinal blood flow, absorption of fluid, electrolytes, and glucose in man is unaffected by exercise. ${ }^{3}$ Although exercise is often prescribed for people with constipation, no studies have been carried out to investigate the effect of exercise on the passage of food through the gastrointestinal tract in man.

In this study we have investigated the effect of prolonged moderate exercise on the gastric emptying and small bowel transit time of a solid meal in seven young healthy volunteers.

\section{Methods}

\section{SUBJECTS}

Studies were carried out on one male and six female healthy volunteers aged between 19 and 21 years. Each subject gave his or her informed consent for the study to be performed and the experimental

\footnotetext{
* Address for correspondence: Dr N W Read. Clinical Research Unit. Floor H, Royal Hallamshire Hospital, Sheffield S10.

Received for publication 15 February 1982
}

protocol was approved by the Ethical Subcommittee of the Sheffield Area Health Authority (Teaching). Female subjects were studied only if they included in their consent a statement to the effect that there was no risk of them being or becoming pregnant during the period of study.

\section{PROCEDURE}

The half time for gastric emptying and the small bowel transit time were determined in all seven subjects, while each exercised in a controlled manner seated on a bicycle ergometer. These were compared with values obtained during a control experiment, during which the same subjects sat upright in a chair. The order of the two studies was randomised.

After an overnight fast, each subject ate a meal consisting of three small Frankfurter sausages (60 $\mathrm{g}), 120 \mathrm{~g}$ baked beans, $150 \mathrm{~g}$ mashed potatoes, and a dessert containing homogenised pineapple, sweetened with sucrose and thickened with custard powder $(75 \mathrm{~g}) .1 .85 \mathrm{MBq}(50 \mu \mathrm{Ci}) 99 \mathrm{~m}$ Technetium were incorporated in the water which reconstituted the mashed potato. This was complexed to sulphur colloid so that it was not absorbed from the gastrointestinal tract and thus served as a marker for gastric emptying. The total weight of the meal was $405 \mathrm{~g}$ and the total calorie intake was $630 \mathrm{Kcal}$. Subjects were allowed to drink $50 \mathrm{ml}$ water with the meal.

The time taken for the subject to eat the meal was measured. The methods used to estimate gastric 957 
emptying and small bowel transit time were identical with those described in our previous publication. ${ }^{4}$ Briefly, gastric emptying was determined by monitoring the radioactive counts over the surface of the stomach by means of single crystal scintillation detector. ${ }^{4}$ Immediately after ingestion of the meal the point of maximum gastric radioactivity was found with the subject lying recumbent on a couch and this position was marked on the surface of the .abdomen. Thereafter the gastric radioactivity was determined by counting over this point for one minute out of every 10 minutes while the subject lay supine. Small bowel transit time was also determined every 10 minutes by measuring the concentration of hydrogen in serial samples of end expired air $^{467}$ using a metallised membrane electrode ${ }^{8}$ The small bowel transit time of the head of the meal was defined as the time from starting to eat the meal to the first sustained rise in breath hydrogen concentration. The latter corresponded to an increase in breath hydrogen concentration of at least 2 parts per million (ppm) above basal values, continuing to rise for at least three successive 10 minute samples.

The exercise consisted of pedalling at a constant rate of 33 pedal revolutions per minute for five out of every 10 minutes, for a total period of six hours (excluding the first 10 minutes after starting to eat the meal). The load on the ergometer was the lowest at which a pulse rate of over 120 beats per minute was recorded. This varied from 1.0 to 1.5 kiloponds according to the size and fitness of each subject, and was determined by carrying out exercise tolerance tests several days before the bowel transit measurements. After each five minute exercise period, the subject sat upright in a chair for about four minutes and then lay down during the final minute so that gastric radioactivity could be measured. In the control experiments, the subject sat on a firm upright chair for nine minutes and then lay down for one minute for measurement of gastric radioactivity.

Pulse rate and blood pressure were recorded at least twice during the 10 minutes before each experiment started and thereafter at regular intervals throughout each experiment, while blood pressure was recorded once towards the end of each period of exercise. In the control experiments pulse and blood pressure were monitored every 10 minutes.

\section{REPRODUCIBILITY STUDIES}

Measurements of the half time for gastric emptying and the small bowel transit time, after ingestion of the test meal described above, were carried out in an identical manner on two separate occasions on 11 subjects (seven male; four female; aged 20 to 29 years), while they lay supine on a couch. The methods used were the same as those described above.

\section{Results}

PULSE RATE AND BLOOD PRESSURE

Exercise caused significant changes in pulse rate and systolic blood pressure (Table), which were sustained throughout the exercise period (Fig. 1).

TRANSIT MEASUREMENTS

The time taken to eat the meal never exceeded seven minutes in any subject.

The stomach appeared to empty in an exponential manner in all experiments. The half time for gastric emptying was shorter in six out of seven subjects during exercise. This difference was statistically significant (Table).

Prolonged exercise was not associated with any significant difference in the small bowel transit time (Table). Five people showed an earlier rise in breath hydrogen concentration when they exercised, whereas in two it was delayed. The average profile of breath hydrogen excretion during exercise was very similar to that obtained during the control study (Fig. 2).

REPRODUCIBILITY OF TRANSIT MEASUREMENTS Duplicate values for gastric emptying and small bowel transit time are shown in Fig. 3. Repeat measurements of the half time for gastric emptying in the same individuals never varied by more than 17 minutes (mean difference $=9 \pm 2$ minutes $(\mathrm{SEM}))$. The average difference in duplicate values for small bowel transit time was $20 \pm 7$ minutes.

Table Average measurements of pulse rate, blood pressure, gastric emptying, and small bowel transit time in seven healthy volunteers during exercise and control experiments

\begin{tabular}{|c|c|c|c|}
\hline & Control & Exercise & $p$ \\
\hline $\begin{array}{l}\text { Pulse rate (beats per minute) } \\
\text { Blood pressure (mm Hg) }\end{array}$ & $72 \pm 1$ & $117 \pm 1$ & $<0.001$ \\
\hline Systolic & $109 \pm 1$ & $119 \pm 1$ & $<0.001$ \\
\hline Diastolic & $73 \pm 1$ & $71 \pm 1$ & $<0.001$ \\
\hline Gastric emptying $t \frac{1}{2}(h)$ & $1 \cdot 5 \pm 0 \cdot 1$ & $1 \cdot 2 \pm 0 \cdot 1$ & $<0.02$ \\
\hline Small bowel transit time (h) & $5 \cdot 1 \pm 0 \cdot 7$ & $4 \cdot 6 \pm 0 \cdot 2$ & $>0.5$ \\
\hline
\end{tabular}

Results are expressed as mean \pm SEM.

Mean pulse and blood pressure were obtained by averaging the values recorded every 10 minutes (towards the end of the exercise period) to obtain a mean value for each experiment in each subject. The mean and standard error of these values in all seven subjects was then calculated.

The degree of significance between paired results ( $p$ value) was determined using Student's paired $t$ test. 

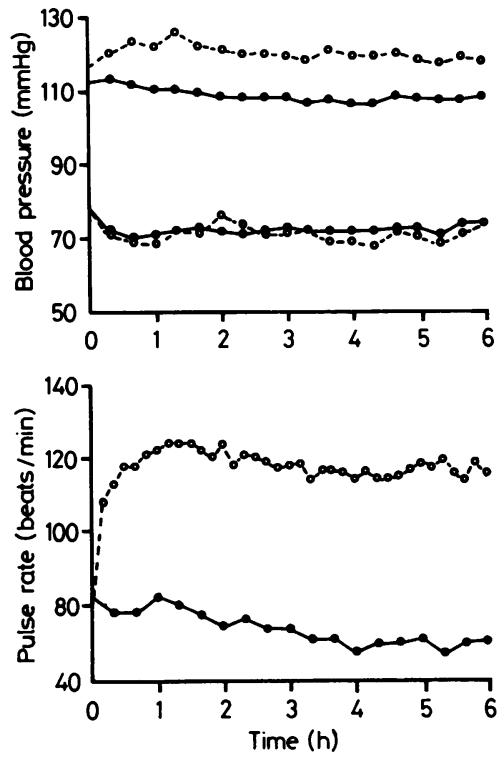

Fig. 1 Effect of exercise on the average systolic and diastolic blood pressure (top) and on the average pulse rate (bottom) in seven normal subjects. $\circ$ Measurements recorded during exercise. - Measurements recorded at rest. Time is measured from the moment the subject started to eat the meal.

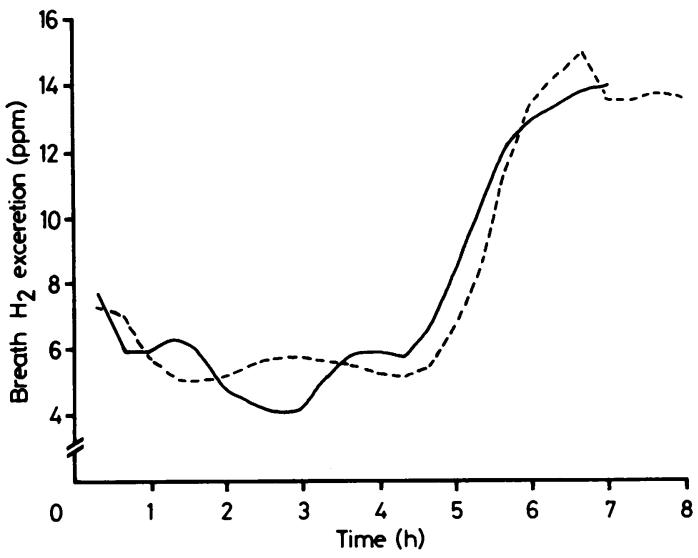

Fig. 2 Comparison of average breath hydrogen excretion profiles during exercise (--.-) and at rest (-) in seven normal subjects, obtained by averaging the concentration of hydrogen in the breath in all seven subjects at 10 minute intervals throughout the study. Time is measured from the moment the subject started to eat the meal.

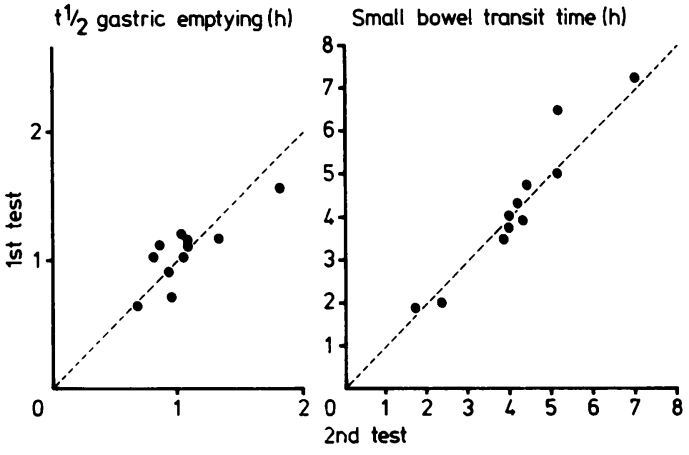

Fig. 3 Reproducibility of duplicate measurements of half time for gastric emptying (left) and small bowel transit time (right) in 11 normal volunteers (seven male, four female, aged 20 to 29 years). The diagonal lines indicate relationships that would exist if duplicate measurements were identical. Time is measured from the moment the subject started to eat the meal.

\section{Discussion}

In this project we investigated the effect of prolonged intermittent moderate exercise, equivalent to cycling 35 miles $(56 \mathrm{~km})$ up a steady incline, on the passage of a solid meal through the stomach and small intestine. The degree of exercise was normalised according to the subject's physiological response and none of our subjects became physically exhausted even though the exercise continued to six hours.

We considered it important to use non-invasive techniques to determine the transit of a meal through the stomach and small intestine, because the presence of a gastrointestinal tube and regular aspiration of gastric contents might have proved intolerable to subjects undergoing six hours of controlled exercise, and because we have recently shown that the presence of a gastrointestinal tube delays gastric emptying and accelerates small bowel transit. ${ }^{9}$

Gastric emptying was monitored by serial estimations of gastric radioactivity using a single crystal scintillation detector. This method can provide as accurate and reproducible an index of gastric emptying as the gamma camera ${ }^{5}$ while using only a tenth of the dose of radiation. We calculated the radiation dosages from standard tables ${ }^{10}$ and found that the total dose to the ovaries generated by a $1.8 \mathrm{MBq}(50 \mu \mathrm{Ci})$ source with a $6.03 \mathrm{~h}$ half life moving through the stomach, small intestine, and 
colon over the course of three days is less than 5 $\mathrm{mrad}$. This is equivalent to the dose received during a standard radiograph of the chest and much less than that received during a radiograph of the abdomen $(500 \mathrm{mrad})$ or a barium meal $(150 \mathrm{mrad})$.

Although the radioactive marker was injected into the liquid which reconstituted the mashed potato, we have previously shown gastric emptying to be unchanged when the same marker is incorporated into the solid phase of the same meal. ${ }^{4}$ Moreover Hinder and Kelly ${ }^{11}$ have shown that the rates of emptying of solids and liquids are similar in meals of relatively homogeneous consistencies, and differ only in meals consisting of discrete solid and liquid components. ${ }^{12}$

The identification of a sustained rise in the concentration of hydrogen gas excreted in the breath provides an accurate index of the transit time of the head of the meal to the caecum. ${ }^{4}$ As the head of the meal leaves the stomach almost as soon as it is ingested, there is no need to correct this value for the rate of gastric emptying.

The observations on gastric emptying have confirmed the early studies of Hellebrandt ${ }^{2}$ and Campbell, ${ }^{1}$ who used barium impregnated meals ${ }^{2}$ or aspiration of gastric contents ${ }^{1}$ to show that gastric emptying was accelerated by moderate exercise carried out just after ingestion, but delayed by severe exhaustive exercise. To our knowledge there have been no previous studies in which the effect of exercise on the transit of a meal through the small intestine has been investigated. The lack of any significant effect on small bowel transit time observed in this study cannot be explained by the variability or poor reproducibility of these measurements, as Fig. 3 shows that values for small bowel transit time in normal subjects using this method are highly reproducible. Moreover, we have previously observed significant changes in small bowel transit time in normal subjects in response to psychological stress ${ }^{13}$ and alterations in the composition of the test meal $^{14}$ (submitted for publication) and significant differences in small bowel transit time in patients with the irritable bowel syndrome compared with normal subjects. ${ }^{15}$

Many of the physiological effects of exercise are thought to be mediated by the release of catecholamines. ${ }^{1617}$ Our results, however, cannot be explained by the classical actions of catecholamines because these would delay gastric emptying and prolong small bowel transit time. ${ }^{18-20}$ There is evidence that psychological stress increases parasympathetic ${ }^{21-25}$ as well as sympathetic tone, and it has been suggested that the variable physiological responses to psychological stress depend on the relative dominance of parasympathetic and sympathetic tone. ${ }^{23}$ If this is true, then it is likely that response to physical stress such as exercise will also vary according to whether the sympathetic or parasympathetic tone is dominant. Thus the reduction in the half time for gastric emptying, induced by moderate exercise, may be explained by a relative dominance in parasympathetic tone, while the delay in gastric emptying, observed by earlier workers in response to severe or exhaustive exercise, ${ }^{12}$ may be explained by a dominance of sympathetic tone. However, exercise is known to cause the release of a variety of hormones nd transmitter substances, ${ }^{26}$ other than acetylcholine and catecholamines, and it is possible that it is the effect of autonomic arousal, modulated by these substances, that is responsible for the response observed in a given individual. In particular, exercise is thought to release endogenous opiatelike agents into the peripheral blood ${ }^{28}$ and these may interact with opiate receptors in the gut ${ }^{29}$ to influence gastrointestinal motility. In general, opiates tend to delay gastric emptying ${ }^{30}$ and small bowel transit, but under certain circumstances they may enhance antral contractions and speed up small bowel motility. ${ }^{31}$

An alternative explanation for the acceleration in gastric emptying observed in this study is that a concomitant reduction in acid secretion, known to occur during exercise, ${ }^{1}$ removes the inhibition of gastric emptying caused by duodenal acidity. ${ }^{32}$

In conclusion, our studies would offer no support to the belief that moderate exercise in a healthy person immediately after a meal may impair the passage of food through the stomach or small intestine.

The authors gratefully acknowledge the expert assistance of Christine Brown, Norma Hobson, Susan Nix, Helen Childs, Sarah Holden, Rick Kashman, Jeanette Longmore, Julia Webber, Norma Simms, and Kim-Lee Swallow, and the help and encouragement of Dr C D Holdsworth, Head of the Gastrointestinal Unit. The study was supported by a grant from the Medical Research Council (G80/0043/8SB).

\section{References}

1 Campbell JMH, Mitchell MB, Powell ATW. The influence of exercise on digestion. Guy's Hosp Rep 1928; 78: 279-93.

2 Hellenbrandt FA, Tepper RH. Studies on the influence 
of exercise on the digestive work of the stomach. II. Its effect on emptying time. Am J Physiol 1934; 107: 355-63.

3 Fordtran JS, Saltin B. Gastric emptying and intestinal absorption during prolonged severe exercise. J Appl Physiol 1967; 23: 331-5.

4 Read NW, Miles CA, Fisher D et al. Transit of a meal through the stomach, small intestine and colon in normal subjects and its role in the pathogenesis of diarrhea. Gastroenterology 1980; 79: 1276-82.

5 Ostick DG, Green G, Howe K, Dymock IW, Cowley DJ. A simple clinical method for measuring gastric emptying of solid meals. Gut 1976; 17: 189-91.

6 Bond $\mathrm{JH}$, Levitt MD. Investigation of small bowel transit time in man utilising pulmonary hydrogen $(\mathrm{H} 2)$ measurements. J Lab Clin Med 1974; 85: 546-55.

7 Metz G, Gassull MA, Leeds AR, Blendis LM, Jenkins DJA. A simple method of measuring breath hydrogen in carbohydrate malabsorption by end expiratory sampling. Clin Sci Mol Med 1976; 50: 237-40.

8 Bergman I, Coleman JE, Evans D. A simple gas chromatograph with an electrochemical detector for the measurement of hydrogen and carbon monoxide in the parts per million range, applied to exhaled air. Chromatographia 1975; 8: 581-3.

9 Al-Janabi MN. The relationship between motor activity in the small intestine and the gastrointestinal transit of food. University of Sheffield: Thesis, 1981.

10 Medical Internal Radiation Dose Committee. Pamphlet No. 10. 1975.

11 Hinder RA, Kelly KA. Canine gastric emptying of solids and liquids. Am J Physiol 1977; 233: E335-40.

12 Meyer JH, Macgregor IL, Gueller R, Martin P, Cavalieri R. 99mTc-tagged chicken liver as a marker of solid food in the human stomach. Am J Dig Dis 1975; 21: 296-303.

13 Cann PA, Read NW, Cammack J et al. Psychological stress and the passage of a standard meal through the stomach and small intestine in man. Gut 1982. (In press.)

14 Read NW, Cammack J, Edwards C et al. Is the transit time of a meal through the small intestine related to the rate at which it leaves the stomach. Gut 1982. (In press.)

15 Read NW. Disordered transit of a meal through the small and large intestine in irritable bowel syndrome. Gut 1980; 21: A906.

16 Banister EW, Griffiths J. Blood levels of adrenergic amines during exercise. J Appl Physiol 1972; 33: 674-6.

17 Galbo H, Holst JJ, Christensen NJ. Glucagon and plasma catecholamine responses to graded and prolonged exercise in man. J Appl Physiol 1975; 38: $70-6$.

18 Jenkinson DH, Morton IKM. The role of alpha and beta adrenergic receptors in some actions of catecholamines on intestinal smooth muscle. J Physiol 1967; 188: $387-402$.

19 Vizi ES, Patan WDM. The inhibitory action of noradrenaline and adrenaline on acetylcholine output by guinea-pig longitudinal muscle strip. BrJ Pharmacol 1969; 35: 10-28.

20 Rees MR, Clark RA, Holdsworth CD. The effect of beta adrenoreceptor agonists and antagonists on gastric emptying in man. Br J Clin Pharmacol 1980; 10: 551-4.

21 Bogdanoff MD, Bogdanoff MM, Wolf SG Jr. Studies on salivary function in man: variations in secretory rate as part of the individual's adaptive pattern. $J$ Psychosom Res 1961; 5: 170-4.

22 Ax AF. The physiological differentiation between fear and anger in humans. Psychosom Med 1953; 15: 433-42.

23 Cannon WB. Bodily changes in pain, hunger, fear and rage. New York: Appleton, 1929.

24 Carruthers M, Taggart P. Vagotoxicity of violence. Biochemical and cardiac responses to violent films and television programmes. Br Med J 1973; 3: 384-9.

25 Zajaczokowaka MM. Acetylcholine content in central and peripheral nervous system and its synthesis in the cat brain during stress and post stress exhaustion. Acta Physiol Pol 1975; 26: 493-7.

26 Hartley LH, Mason JW, Hogan RP. Multiple hormonal responses to graded exercise in relation to physical training. J Appl Physiol 1972; 33: 602-6.

27 Lamb DR. Physiology of exercise: responses and adaptations. 1st edn. New York: Macmillan, 1978.

28 Guillemin R, Vargo T, Rossier J et al. Beta-endorphin and adrenocorticotrophin are secreted concomitantly by the pituituary gland. Science 1977; 197: 1367-9.

29 Peat CB, Snyder SH. Opiate receptors: demonstration in nervous tissue. Science 1973; 179: 1011-4.

30 Chapman WP, Rowlands EN, Jones CM. Multipleballoon kymographic recording of the comparative action of demerol, morphine and placebos on the motility of the upper small intestine in man. $N$ Engl $J$ Med 1950; 243: 171-7.

31 Neely J. The effect of analgesic drugs on gastrointestinal motility in man. Br J Surg 1969; 56: 925-9.

32 Shapiro $\mathrm{H}$, Woodward ER. Inhibition of gastric motility by acid in the duodenum. J Appl Physiol 1955; 8: $121-7$. 